\title{
OS LIMITES DA MÚSICA NO RENASCIMENTO SEGUNDO A PRECEPTIVA DE GIOSEFFO ZARLINO (1517-1590)
}

\author{
Delphim Rezende Porto ${ }^{l}$ \\ Universidade de São Paulo - SP \\ E-mail:delphim@usp.br
}

\section{Resumo:}

Esse artigo aborda a preceptiva elaborada por Gioseffo Zarlino, músico e tratadista ativo em Veneza no século XVI, a respeito da extensão e limite do conceito de 'Música' difundido literariamente especialmente nas "Instituiçóes Harmônicas" - tratado publicado pelo autor entre 1558 e 1589. Encomiada pela perfeição alcançada em seu tempo, enquanto Arte e Ciência, a Música representa ali mais que o exercício dos sons, mas uma série de conhecimentos extrínsecos ao senso hodierno ligado quase que exclusivamente à performance. Coligindo e traduzindo as mais relevantes passagens referentes ao assunto, pretendemos oferecer um panorama epistemológico das chamadas "Divisóes da Música", que são os fundamentos genéticos da produção musical no Renascimento.

Palavras-chave:Teoria musical. Análise. Renascimento italiano. Gioseffo Zarlino. Retórica Musical.

Título em inglês: The limits of music concepton Renaissance according to the Gioseffo Zarlino's preceptives (1517-1590).

\section{Abstract:}

This article deals with the preceptive elaborated by Gioseffo Zarlino, a musician and tratadist active in Venice during the sixteenth century, regarding the extent and limit of the concept of Music diffused in the 'Harmonic Institutions' - a treatise published by the author between 1558 and 1589 . Describe das Perfetta, as Art and Science, Music represents there more than the exercise of sounds, but a series of knowl-
1. O autor recebe bolsa de doutorado (processo $n^{\circ}$ 2014/26766-2) da Fundação de Amparo à Pesquisa do Estado de São Paulo (FAPESP). As opiniōes, hipóteses e conclusōes ou recomendaçóes expressas nesse material são de responsabilidade do autor e não necessariamente refletem a visão da FAPESP. 
edge extrinsic to the today's sense where it isconsidered almost exclusively onthe music performance field. Collecting and translating the most relevant passages related to the subject, we intend to offer an epistemological panorama of the socalled "Divisions of Music", which are the genetic foundations of musical production during the Renaissance.

Keywords: Music Theory. Analysis. Italian Renaissance. Gioseffo Zarlino. Musical Rethoric.

\section{INTRODUÇÃO}

Segundo a opinião de Gioseffo Zarlino (1558), seguida por G. Maria Artusi (1600) e Girolamo Diruta (1593), a música realizada em seu tempo por valent'huomini como Adriano Willaert, Cipriano de Rore, Costanzo Porta, Andrea e Giovanni Gabrielli, Luzzasco Luzzaschi - representantes da Escola Veneziana, como afirmado por Artusi (1603, p. 5) na Segunda parte de seu tratado sobre as Imperfeiçóes da Música Moderna, e da Escola Romana - na qual reinam G. P. Palestrina, Giovanni De Macque e outros mestres - havia chegado a um tal ponto de desenvolvimento e brilho que se poderia afirmar, como reclamado, que era perfeita. O desenvolvimento e sofisticaçáo do contraponto, sobretudo encontrados na polifonia sacra vocal e, especialmente, nos Ricercari instrumentais para vários instrumentos são, de fato, notáveis. Sobre os últimos, afirma TAMMINGA (2010) no proêmio à edição da Musica Nova, publicada originalmente em 1540, que são a grande contribuição de Willaert e sua Escola contrapontística -uma vez que empreenderam um particular tratamento temático dos soggetti rítmicos e melódicos que, imitados em todas as vozes, são ordenados por meio decadências. A sucessão bem composta dos diversos soggetti, entáo, emprestariam ao discurso sonoro grande compreensibilidade e efeito à imitação da natureza - através da mimese de um discurso oratório. É possível, desse modo, que Zarlino reúna os argumentos para as Instituiçóes Harmônicas (1558) considerando como premissa a perfeição e sofisticação da arte já alcançada por seus pares e por Adriano Willaert, seu mestre - uma vez que essa obra constitui verdadeiro monumentum à memória de sua tradição 
musical. Como, porém, o entendimento da Música nesse período histórico é bastante amplo, é necessário verificar os limites de seu conceito para compreendermos onde está sua 'perfeição' - muito embora, no plano de encômio e louvor, tanto na literatura tratadística quanto naquela de cortesania, se percebem pacíficas na opiniáo, como expóe Artusi (1600, p. 9), de que:

[...] ao tratar [...] dessa Ciência, a qual, segundo a opiniáo de muitos, é chegada a tão completa perfeiçâo que não pode, nela, se acrescer coisa alguma; [...] [pois] se ouvem tantos e táo variados tipos de peças musicais, empreendidos à várias vozes em coros divididos com muitos e diversos instrumentos, em tantas harmonias, que faz o homem, como se costuma dizer, transbordar $[\ldots] .^{2}$

\section{A PRECEPTIVA MUSICAL DE GIOSEFFO ZARLINO}

Uma primeira aproximação das várias definições da Música, que tomaremos especialmente na obra de Zarlino, relaciona-se ao conceito de Harmonia - que, naquela tradição, é cunhada a partir do conceito de discordante concordia referida originalmente na doutrina de Empédocles. Segundo sua preceituação, uma primeira noção de Harmonia, compreendida nos diversos sons administrados pelos músicos, consonantes e dissonantes, estabelece-se por razóes matemáticas nas proporçóes numéricas que resultam em sons que, ora suavemente, ora de modo áspero, são produzidos por movimentos lentos - no caso de emissóes graves - ou rápidos, na união de duas frequências diferentes, uma mais grave e outra mais aguda. A consonância apresenta, em uma só proporção, o encontro harmonioso de um som com outro - o que, pelo contrário, não acontece quando um som não quer unir-se ao outro, resultando em uma desproporção - que Zarlino declara como 'dissonância'. A Harmonia Própria, portanto, consiste no concerto de cordas ou vozes que, ao modularem em uma peça musical (cantilena) não ofendem de nenhum modo os sentidos ao mesclar sons de diferentes alturas (ou frequências matemáticas) e, por isso, podem dispor o ânimo à diversas paixóes. Não apenas, contudo, a Harmonia revela-se no uso de consonâncias, diz o autor no mesmo XII capítulo da segunda parte das Instituições Harmônicas (1589, p. 98):
2. “[...] trattare $[\ldots] \mathrm{di}$ questa Scienza, la quale appresso molti, è giunta à tal colmo di perfettione, che non vi si può aggiungere cosa alcuna; [...] si sentono tante, e tante variate sorti di Cantilene; diuise à Vicenda in tanti Chori, con tanti variati Instromenti, e tante Harmonie che quasi riduce l'huomo, come si dice, di se stesso fuori $[\ldots]$ ". 
3. “[...] Et questa

Harmonia non solamente nasce dalle Consonanze; ma dalle Dissonanze ancora; percioche i buoni Musici pongono ogni loro studio di fare, che nelle Harmonie le Dissonanze accordino; \& che com maruiglioso effeto consonino $[\ldots]$ ".
[...] E esta Harmonia não apenas nasce a partir das Consonâncias - mas, também, de Dissonâncias - uma vez que os bons músicos dedicam todo seu estudo para fazer que ambas concordem e, com maravilhoso efeito, consonem $[\ldots]^{3}$

A eficiência, no entanto, da sonoridade não está apenas condicionada à boa administração das consonâncias e dissonâncias em uma "harmoniosa consonância" - como ele a nomeia - mas, sim, na uniāo perfeita entre o número (as frequências sonoras) e a Oração, ou seja, na conjunção da imitação da fala humana com os sons. Essa imitação consiste na regência dos diferentes ritmos e metros e é mais eficiente na comoção da audiência quando consegue (1589, p. 98) combinar bem o "Rhythmo, ueramente al Metro côproportione", ou seja, o Ritmo ao metro com proporçóes sonoras. Referindo-se ao conceito de Melodia estabelecido por Platáo no terceiro livro "Da República", Zarlino sintetiza a perfeição desse conceito de Harmonia na união de três elementos: a Harmonia Própria, o Ritmo e a Oração.

É através dessa união, que traz em si uma dimensão matemática e retórica, que Zarlino vai discutir o poder de persuasão que a Música pode ter quando bem exercida. Cada homem, prossegue o autor, naturalmente mais se deleita naquela harmonia que é (1589, p. 91) "mais semelhante, conveniente, proporcionada à sua natureza" e segundo àquilo que é disposto pelo orador musical. Afirma igualmente o autor, referindo-se à doutrina de Aristóteles na Ética, que as virtudes morais e os vícios, não sendo inatos, ocorrem no homem a partir de hábitos e costumes que ele frequenta, de modo que as operações realizadas pelo indivíduo têm consequências no exercício particular de todas as suas atividades. Um tocador ou um escritor que tem por hábito, diz Zarlino, de frequentar tópicos tristes, consequentemente torna-se triste; de outro modo, aquele que pratica a justiça, segundo a doutrina, tornase justo; ou, ainda, aquele que pratica com muita acuidade, torna-se bom e excelente, tal que há um paralelo entre o que se pratica enquanto operação e os hábitos: dos bons imprimem virtudes; dos tristes, pesares. Sendo, portanto, os números $\mathrm{e}$ as harmonias similares às paixões humanas, como refere Aristóteles no Problema 29 - sempre na leitura de Zarlino - se pode dizer que habituar-se à harmonias e números equivale a acostumar e dispor-se à paixóes e hábitos morais, bem 
como à costumes particulares, pois ao ouvir um discurso musical proporcionado à ira ou ao amor, por meio do artifício se vai dispondo e dirigindo o ânimo do Homem à essa paixão, por exemplo. Quanto maior a semelhança das harmonias às paixôes, mais eficiente será a operação; contudo, aquele que mais vezes tiver frequentado um certo tipo de harmonia, mais prazer e deleite observará ao ouvi-la, por já estar acostumado a ela - pois, como diz Virgílio - "Numerosmemini, si verba tenerem" que na tradução das Bucólicas em língua espanhola por Gregorio Marans I Siscar (1795, tomo I, p. 161) quer dizer "latonadillabienla sé, si no que no me acuerdo de los versos"; para isso, portanto, concorrem o Ritmo combinado aos Números sonoros (as frequências musicais) - compreendendo que 'Ritmo' sejam os diferentes metros e pés que ordenam os versos de uma oração.

As diferentes tradiçóes musicais, entretanto, apresentam variadas versóes para seus conceitos, fins e artífices. Zarlino (1589, p. 25), assim, recolhe as doutrinas antigas que identificam a origem da palavra música com a sua consequente explicação:

Ocorre que alguns têm a opinião que ela tenha origem no verbo

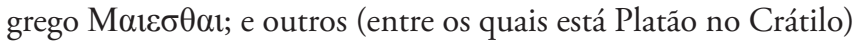
que venha de $M \omega \sigma \theta \alpha$, que quer dizer procurar ou investigar - como acima está descrito. Alguns quiseram ainda, que viesse da palavra $\mathrm{M} \omega \mathrm{u}$, de origem egípcia ou caldéia, unida à palavra grega $\rceil \chi 0 \sigma:$ uma significa 'água' e a outra, 'som' - quase como se tivesse, pelo som das águas, sido descoberta, como diz Giovanni Bocaccio no livro da Genealogia dos Deuses. Verdadeiramente náo me desagrada tal opiniáo, pois concorda com a de Varrão que entende que, de três modos a Música tenha origem: a partir do som das águas, pela repercussáo do ar, e através da voz (ainda que Agostinho entenda de outro modo [no De DoctrinaChristiana, livro 2, capítulo 14). Alguns outros também consideraram que fosse dito que junto às águas foi descoberta [a música], uma vez que Pan, deus dos pastores, foi o primeiro, como narra Plínio, que fez [da ninfa] Siringe transformada em caniço junto ao rio Ladon, na Arcádia, uma Sampogna pastoral [a chamada flauta de Pan], como diz o poeta [Virgílio, nas Eclógas]:

Pan foi o primeiro que ensinou a unir vários caniços [tubos] com cera. 
4. "[...] conciosia che alcuni hanno hauuto opinione, che ella habbia origine dal verbo greco [Maiesthai]; et altri (tra i quali è Platone nel Cratilo) da [mosthai], cioè dal cercare, o inuestigare; come di sopra si è mostrato. Et alcuni hanno hauuto parere, che sia detta da [mou] voce Egittia, o Caldea, et da [echos] voce Greca; che l' vna vuol significare Acqua, et l' altra Suono; quasi per il suono delle acque ritrouata: della quale opinione fu Giouanni Boccaccio ne i libri della Geneologia delli Dei. Et in vero non mi dispiace: percioche è concorde alla opinione di Varrone, il qual vuole, che in tre modi naschi la Musica; o dal suono delle acque; o per ripercussione dell' aria; o dalla voce: ancorache Agostino dica altramente. Alcuni altri istimarono, che cosi fusse detta: perche appresso l' acque fu ritrouata, et non per il suono delle acque; mossi per auentura da questo, che Pan dio de pastori fu il primo (come narra Plinio) che della sua Siringa conuersa in canna appresso Ladone fiume di Arcadia, fece la Sampogna pastorale; il che afferma il Poeta dicendo;

Pan primus calamos cera coniungerepluresInstituit. Et quantunque queste opinioni siano buone, tuttauia quello che a me par più ragioneuole, et più mi piace è l' opinione di Platone, che ella sia nominata dalle Muse, alle quali (come dice Agostino) è conceduto vna certa onnipotenza di cantare: et vogliono li
Embora essas opiniôes sejam boas, aquilo que, todavia, me parece mais razoável e agrada, é a opinião de Platão que o nome Música tenha sua origem nas Musas, às quais, como afirma Agostinho, foi concedida uma certa onipotência para cantar. Declaram os poetas que sejam filhas de Zeus e Mnemósine (Memória) - e dizem bem, pois se o homem não guarda os sons e os intervalos musicais na memória, não pode obter muito proveito - uma vez que deles não adianta somente escrever. Diz ainda Quintiliano, que toda Ciência e toda Disciplina consiste na memória pois em vão nos é ensinado aquilo que ouvimos e não guardamos na mente. ${ }^{4}$

As variadas possibilidades oferecidas pelo autor são de notável agudeza, como se pode verificar, e auxiliam, no âmbito do discurso, a justificar práticas tão distintas quanto distantes que a Música tinha em seu tempo. A etimologia retórica empregada como recurso oratório, expediente regular dos oradores, explica três variantes que Zarlino colige para suas definiçôes. A primeira e segunda versóes, descrevem a origem do termo a partir da junçáo do termo $\mathrm{M} \omega u$, que quer dizer 'água', unido à palavra grega $\rceil \chi 0 \sigma$, 'som', que exibe a doutrina reportada à Varrão que estabelece a água, o ar e a voz, como meios para o aparecimento do som, e também recupera a origem, por assim dizer, aquática da Música, remetida à história de Pan. No livro da Genealogia dos deuses pagãos, publicado em 1472 em língua latina, Giovanni Bocaccio - traduzido ao vernáculo italiano por Giuseppe Betussi (1581, fl. 10) - como explicitado por Zarlino, de fato esclarece tal relação e amplia a descoberta da música por Pan considerando-a como um espelhamento do som no universo:

[...] Dele, Teodôntio, narra uma fábula. Diz que aquele, com palavras desafiou o Amor provocando-o; tendo se enfrentado, foi por ele vencido, e por ordem do vencedor, amou Siringa, ninfa da Arcádia - a qual tendo sido zombada pelos Sátiros, também desprezou ser desposada por ele. Pan, assim, impelido pelo amor e seguindo aquela que fugia, viu-a chegar junto ao rio Ladon mas, impedida por seu curso, ali teve que parar; vendo que não poderia escapar de Pan, com oraçóes, começou a pedir auxílio às ninfas, que atendendo aos seus pedidos, a transformaram em caniços do pântano - os quais ao se chocarem foram percebidos por Pan como sonoros. Assim, pela afeiçấo à jovem por ele amada, comovido pelo deleite promovido pelo som, com prazer recolheu aqueles caniços e, em tamanho desigual, cortou seis deles e - como dizem - compôs uma fístula [flauta] e com ela, de modo inédito, tocou e cantou, como também Virgílio sustenta. [...] 
Como, acima, Pan foi declarado ser a natureza, aquilo que quisessem simular dizendo ter sido vencido pelo amor, facilmente imagino ser verdadeiro. Como rapidamente a natureza foi produzida por esse criador, no mesmo instante começou a operar e, deleitando-se da sua obra, aquela começou amar, assim movida pelo deleite, submeteu-se ao amor. Siringa, entấo, a qual dizem ter sido amada por Pan, como dizia Leôntio, é chamada em grego de Sirim e, que em latim, soa como Cantora de Deus. Podemos, portanto, dizer que Siringa é a melodia dos céus, ou das esferas (como prefere Pitágoras), a qual se realizava, ou realiza, através dos vários movimentos dos círculos das esferas entre si. Consequentemente, como coisa muito agradável a Deus e à natureza, pela operadora da natureza, de fato, é amada. Ainda, como quisermos que Siringa (operando ao nosso redor e sobre os corpos celestiais) - seja uma obra da natureza harmonizada com tanta ordem, que enquanto é guiada - de modo contínuo - tanto por incerto ou determinado fim, nos presenteia com uma harmonia semelhante àquela dos bons cantores - 0 que é muito agradável a Deus. ${ }^{5}$

Além da referência acima examinada, Zarlino também recolhe os entendimentos de que a Música teria sua origem "nas Musas" - em acordo com a doutrina exposta por Platão, no Primeiro Alcibiades, e por S. Agostinho, no De Musica - e que são filhas de Zeus e Mnemósine, ou Memória. Tal estirpe, notável por seus pais, ainda se faz mais conveniente, amparada na literatura retórica - especialmente por Quintiliano, no livro II, capítulo 2, onde se trata da Memória para o orador - pois os intervalos e sons da música não são úteis se não retidos na memória, pois deles, não há papel que possa escrevê-los sonoramente.

O terceiro conceito que Zarlino reporta, no entanto, corresponde à ideia de Música como investigação ou procura - outro vocábulo para especulação - que se articula no termo Maiestha, dimensão que vai ser central nas divisões elaboradas pelo autor.

\section{DA MÚSICA TEÓRICA}

Diz-nos Zarlino, no segundo capítulo da Primeira parte das Instituiçôes Harmônicas (1561, p. 20), que há na Música, assim como em outras Ciências, divisóes convenientes para o
Poeti, che siano figliuole di Gioue et di Memoria; et dicono bene: percioche se l' huomo non ritiene li suoni et gli interualli delle voci musicali nella memoria, non fa profitto alcuno; et questo auiene: perche non si possono a via alcuna scriuere: tanto più, che ogni scienza, et ogni disciplina (come vuole Quintiliano) consiste nella memoria: conciosia che in vano ci è insegnato, quando quello che noi ascoltiamo dalle menti nostre si parte."

5. “[...] Di cui Theodontio recita tal fauola. Dice che quello con parole prouo il Amore \& uenuti infieme a battaglia fu da lui uinto, onde per comandamento del uincitore amò Siringa ninfa d'Arcadia, la quale effendofi prima fatta beffe di Satiri fprezzò anco il maritaggio di quello. Onde Pan conftretto dal'amore, $\&$ feguendo quella che fuggiua, auenne ch'ella giunta al fiume Ladone, e impedita da quello iuifi fermò, \& ueggendo non poter fchifar Pane, con preghi incominciò dimandare l'aiuto delle ninfe, per opra delle quali fu conuertita in canelle di paludi le cui fentendo Pan per lo mouere de uenti, mentre l'una con l'altra fi percuoteua effere canore, coli per la affettiene della giouane da lui amata, come per la dilettatione del fuono commolfo, uolentieri tolfe di quelle canne, con di quelle tagliatone fei difeguali, compofe (come dicono) una fiftola, e con quella prima fonò, \& cantò, come 
ancho pare, che Virgilio dimoftri. [...]

Et perche fopra Pan è stato detto efferui la natura, quello, che uoleffero fingere dicendo effere stato uinto dall'amore facilmente m'imagino poterfi uedere. Percioche come fubito la natura fu prodotta da effo creatore, tan tofto incominciò operare, \& dilettandofi dell'opra fua, quella incominciò amare, cofi moffa dal di letto fi fottopofe allo amore. Siringapoi, la quale dicono effere stata amata da Tan,come diceua Leontio,uien detta Grecamente da Sirim,che Latinamente , fuona, cantante a Dio onde potremo dire Siringa, effermelodia dei Cieli, o delle fphere, laquale(come piacque a Pitagora)fifaceua, ouero fi fa da uari mouimenti tra fe dei circoli delle fphere. Et per confequenza come cofa gratiffima a iddio, e alla natura, dalla natura operatrice uiene amata".

6. "[...] tanto più, che se le mani non operassero quello, che dalla ragione gli è commandato, vanamente et senza frutto alcuno si affaticarebbeno [...]". conhecimento e estudo aprofundado das mesmas. Segundo a tradição por nosso autor reportada, pitagórica e boecianapor excelência, a Música apresenta duas basilares secções: a primeira, relativa à Especulação científica e a uma dimensão puramente teórica - próprio das verdades intelectuais - e, a segunda, exclusivamente concernente à Prática e a um exercício estritamente pragmático. A primeira divisão, segundo Zarlino, toma argumento da noção de especulação e serve para desenvolver as ciências, bem como fornecer novos argumentos para sua ampliação e aprofundamento. A dimensão Prática, contudo, visa somente operar - como o é, semelhantemente, o escrever e a fabricação manual de objetos - e está submissa àquilo que dá apetite ao intelecto e à razão - a especulação - uma vez que é unânime em todas as artes e ciências, que é mais nobre o entendimento pelo qual se obra que o operar por si mesmo.

Pela razão, prossegue Zarlino, temos a alma que, por seu comando, submete ao corpo suas ordens, já que, por sua nobreza, pode vencer a matéria e seus caprichos e dar-lhes sentido (1561, p. 20): "se as mãos não operassem aquilo que a partir da razão lhes comanda, em vão e inutilmente trabalhariam" 6. Consequentemente, no âmbito musical, mais nobreza e dignidade tem o conhecimento das razóes teóricas da arte, que o puro domínio prático dela. A Especulação, contudo, muito embora não necessite de uma aplicação prática, tem no seu agente, aqui chamado de 'especulativo', uma ação limita$\mathrm{da}$ - pois não pode produzir, no ato, coisa alguma que tenha descoberto sem o auxílio de um artífice ou de um instrumento musical.

De fato, considera Zarlino, no âmbito musical, que a maior perfeiçãao do opífice 'especulativo' - não necessariamente da 'especulação' - reside justamente na harmonia e união que pode encontrar com o conhecimento prático. Desse modo, para que, provas e descobertas teóricas não sejam - por assim dizer - em vão e alcancem seu último fim - que é para Zarlino, o (1561, p. 20) "exercício dos instrumentos naturais e artificiais" - a Teoria e a Prática, na música, deveriam andar sempre unidas, pois também, "o artífice sem auxílio da razão jamais poderia alcançar, em sua obra, perfeição alguma, uma vez que, na Música (considerando-a em sua mais alta perfei- 
ção), essas duas partes estão tão ligadas, que [...] não se pode separar uma da outra" 7 .

Hodiernamente, embora também haja uma leitura de oposição do conceito de Teoria e Prática, assim como no Renascimento e nessa literatura, é necessário observar que não se trata da mesma questão. Também na primeira porção da primeira parte das Instituiçóes Harmônicas, Zarlino (1589, p. 10) traça sua própria definição da palavra 'Música', que em seu tempo possui diversos significados - e rapidamente trouxemos à luz. $\mathrm{O}$ próprio autor no capítulo décimo do mesmo livro faz uma digressão do grande número de possíveis interpretaçóes e suas prováveis origens. Contudo, desde a elaboração pitagórica da ideia de harmonia universal, passando pela tradição platônica da atribuição do conceito de música à astronomia, ao entendimento cunhado por Empédocles (e sempre lembrado na tratadística em Zarlino e Diruta) de "discordante concordia” - a palavra 'Música', fortuna de Boécio no De institutione Musica, livro I, capítulo 2, pode ser considerada em três níveis hierárquicos: 1) Mundana, 2) Humana e 3) Instrumental ${ }^{8}$.

[...] Que ninguém se surpreenda que eu tenha dito ser a Música, uma ciência especulativa, pois considero ser possível que se possa dispor dela intelectualmente ainda que não a exercite através dos instrumentos -naturais ou artificiais [...].9

Por Música Mundana, Zarlino diz (1561, p. 16) da harmonia das "coisas que se veem e se conhecem no céu" 10 , como o movimento dos astros no universo, por exemplo. Por Humana, diz Zarlino que é aquela harmonia que observamos principalmente em nós mesmos, sobretudo no equilíbrio dos humores e temperamentos que regulam o corpo humano em si. Por música Instrumental, Zarlino emprega outra terminologia (na divisão); ele a chama de música Orgânica, ou seja, aquela relativa ao órgão - instrumento que compreenderia todos os outros, conforme a tradição estabelecida por Plínio no seu tratado de arquitetura ${ }^{11}$ - e, portanto, da harmonia de todos os instrumentos, tanto os naturais (todos os órgãos envolvidos no canto - língua, palato, pulmão, garganta, etc) quanto os artificiais (aqueles produzidos pela arte do homem).
7. "quando non si riducesse all' vltimo suo fine, che consiste nell' essercitio de naturali, et artificiali istrumenti, col mezo de i quali ella viene a conseguirlo: si come ancora l' artefice senza l' aiuto della ragione mai potrebbe condurre l' opera sua a perfettione alcuna. Et per questo nella Musica (considerandola nella sua vltima perfettione) queste due parti sono tanto insieme congiunte, che per le assegnate ragioni non si possono separare l' vna dall' altra".

8. Cícero também discute a Música Mundana no famoso "Sonho de Cipião" - De Re Publica, livro VI, capítulo 18.

9. “[...] Ne si marauigli alcuno, ch' io habbia detto la Musica essere scienza speculatiua: percioche tengo, che sia possibile, che vno possa quella possedere nell' intelletto; ancora che non l' esserciti con li naturali o artificiali istrumenti. [...]".

10. "[...] Dicoche

si veggono et conoscononelcielo [...]".

11. Diruta (1593) se utiliza desse lugar comum da Antiguidade para o encomio do órgão - para ele, instrumento acima de todos os outros, exceto da voz humana. 
12. "L”animastica", termine riferibile alla platonica anima del mondo, contiene la musica mondana e la musica humana di Boezio ossia armonia del macrocosmo e armonia del microcosmo, cosmologia musicale e antropologia musicale".

\section{AS DIVISÓES DA MÚSICA OFERECIDAS POR ZARLINO}

Zarlino apresenta, entretanto, uma outra divisão do conceito de Música (que estamos discutindo) que não corresponde exatamente àquela recolhida por Boécio. Para o tratadista, as duas primeiras divisōes da Música são aquelas "Animastica" - que se subdivide aqui em Humana e Mundana, com os mesmos entendimentos acima expostos - e a Orgânica - também subdivida, em Artificial e Natural (de acordo com a natureza do instrumento). Seguem-se outras subdivisōes que concluem com os tipos de ação empregados na produçáo do som físico nos instrumentos musicais (de sopro, corda ou "de bater" - como traduz Fernandez (1626), ao vernáculo português, o termo "battere").

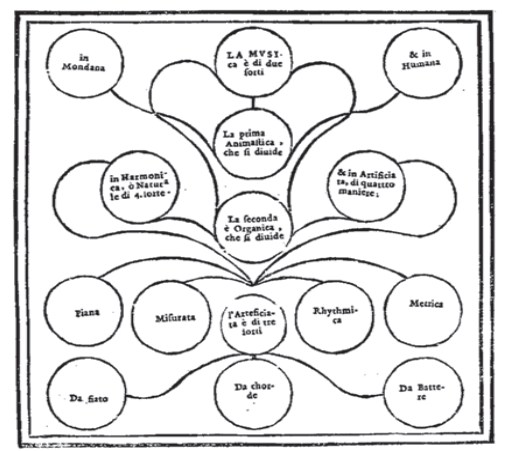

Fig. 1: Zarlino (1589, p. 15) - Detalhe das divisóes da Música.

Por Música Animástica, da Anima, Alma, Zarlino compreende a Música Humana e a Música Mundana, como segue. Paolo Gozza (2000, p. 10) afirma, ainda, que essa divisão zarliniana baseia-se na ideia platônica da alma do mundo, ou seja, na harmonia do macrocosmo e na harmonia do microcosmo, na cosmologia musical e na antropologia musical:

A Animástica, termo que se refere à platônica alma do mundo, contém a Música Mundana e a Música Humana de Boécio, ou seja, a harmonia do macrocosmo e a harmonia do microcosmo, a cosmologia musical e a antropologia musical. ${ }^{12}$ 


\section{DA MÚSICA MUNDANA}

Considerando, portanto, a Música no seu plano retórico-teórico, Zarlino compreende a chamada Música Mundana como parte do binômio Animastico (relativo à Anima, Alma) que também abarca a Música Humana; sobre o tema, o autor dedica os capítulos VI e VII das Istitutione - os quais analisaremos a seguir. A m. Mundana é aquela Harmonia, como define Zarlino, que não apenas está relacionada ao que se vê e conhece no Céu, mas também na relação dos Elementos naturais entre si e na variedade de tempo que apresentam, uma vez que as distâncias e as diversas partes das esferas celestes, sua natureza e posicionamento, o lugar dos sete planetas - que são a Lua, Mercúrio, Vênus, o Sol, Marte, Júpiter e Saturno - são considerados pelos antigos filósofos, sempre segundo Zarlino, especialmente por Pitágoras como emissores de som, pois uma grande máquina, de veloz movimento, não se movimenta e funciona sem fazer grande clangor. Zarlino igualmente observa a conexão que há entre os movimentos celestes descritos pela tradição e a música que desde sempre acompanhou os ritos de religião, tanto os sacrifícios que faziam quanto para acompanhar as exéquias, indiciando o espelhamento que existe entre o Universo e o Homem (1589, p. 17):

Este [som] é aquele, que composto por diversos intervalos, não obstante as suas diferentes proporçóes, é gerado pela distância e movimento desses círculos, que ao temperar, assim, agudos com graves, emitem diversos sons - uma vez que não se pode fazer grandes movimentos em silêncio e, como estabelece a Natureza, que os extremos, de uma parte soem grave, e de outra, aguda. Por essa razão, o sumo curso do céu estrelado quando se move mais veloz emite sons agudos e fortes, enquanto que, lunar e mínimo, emite sons deveras grave. Diz isso Túlio seguindo a opiniáo de Platáo que, para demostrar e ilustrar que esse movimento gerava uma Harmonia, dizia que cada esfera era encimada por uma Sereia - que quer dizer Cantora de Deus - assentada. Hesíodo, também, na sua Teogonia, e nesse mesmo sentido chamou ỏopavía a oitava Musa, que é apropriada à oitava esfera, de ỏvpavós, que em grego quer dizer 'o Céu'. E, para mostrar que a nona esfera fosse aquela que dá à luz a grande e concorde unidade dos sons, a denominou $\kappa \alpha \lambda \lambda ı$ ó $\pi$, que significa 'ótima voz', querendo demonstrar a Harmonia que resulta de todas essas outras esferas - como declarou o poeta [Virgílio na Eneida, IX]: 
13. "Questo è quello, che congiunto per inequali interualli, nondimeno distinti per compartita proportione, è fatto dal sospingere $\&$ dal muouere di essi circoli; il quale temperando le cose acute con le graui, equalmente fa diuersi concenti; Perche non si possono fare si gran mouimenti con silentio, \& la Natura porta, che gli estremi dall'vna parte grauemente, $\&$ dall'altra acutamente suonino. Per la qual cosa quel sommo corso del cielo stellato, il cui riuolgimento è più veloce, si muoue con acuto \& più forte suono; \& questo lunare \& infimo con grauissimo. Questo dice Tullio, seguendo il parer di Platone; il quale per mostrare, che da tale riuolgimento nasca l'harmonia, finge che a ciascuna sphera soprasieda vna Sirena: Percioche Sirena non vuol significare altro che Cantatrice a Dio. Et medesimamente Hesiodo nella sua Theogonia accennando questo istesso, chiamò ỏupavía l'ottaua Musa, che è appropiata all'ottaua sphera, da óvpavós, col qual nome da i Greci vien nominato il Cielo. Et per mostrare, che la Nona sphera fusse quella, che partorisse la grande \& concordeuole vnità de suoni, la nominò

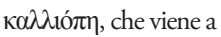
significare di Ottima voce; volendo mostrar per questo l'harmonia, che risulta da tutte quell'altre sphere; come si vede accennato dal Poeta quando disse;

Vos o Calliope aspirate canenti;

inuocando solamente Calliope nel numero del più, come la principale, \& come quella al cui solo volere si muoueno, \& si girano tutte l'altre. Et tanto hebbero gli
"Agora tu Calíope me ensina

E vós Musas me dai suficiente

Favor, pera que cante quanta morte

Alli causou de Turno o ferro forte."

(VIRGILIO, 1670, fl. 64, tradução de João Franco Barreto)

Invocando particularmente Calíope, entre as demais, como principal e como aquela, cujo querer move e gira todas as outras. E tanto os antigos consideraram essa opiniáo como verdadeira, que nos sacrifícios, eles usavam instrumentos musicais e cantavam alguns Hinos compostos de versos sonoros - os quais continham

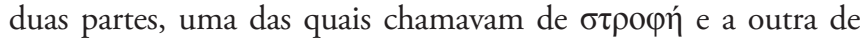

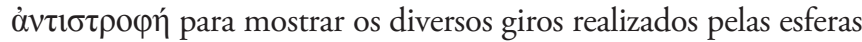
celestes, sendo que uma, compreenderia os movimentos que as esferas fazem do Oriente ao Ocidente, e a outra, os movimentos que fazem as outras esferas e planetas que procedem ao contrário, segundo a opiniáo de alguns, do Ocidente ao Oriente. E com tais instrumentos acompanhavam, ainda, os corpos de seus mortos à sepultura, uma vez que acreditavam que depois da morte as almas retornariam à origem da doçura da Música, ou seja, ao Céu. Tal costume observaram os Judeus antigamente quando da morte de seus parentes - do que temos claríssimo testemunho no Evangelho [de Mateus, 9), no qual está descrita a Ressurreição da filha do príncipe da sinagoga, onde estavam também instrumentos musicais e tocadores, aos quais mandou Nosso Senhor que parassem de tocar. E faziam isso, segundo Ambrosio [SuperLucam, cap. 8, livro VI] para observar o uso dos seus antigos, que por esse expediente, impeliam os presentes a chorar seus mortos. ${ }^{13}$

A doutrina visitada por Zarlino para esse fim, compreende que a alma, estando presa ao corpo humano, ao ser induzida pela Música, pode, pela natureza espelhada dos céus, rememorar sua natureza celeste. Do mesmo modo que não podemos apreender o Sol diretamente senáo por seus raios, do mesmo modo os nosso ouvidos não podem captar a doce grandeza das harmonias celestes senão indiretamente (1589, p, 17):

Muitos ainda tinham a opiniáo de que, nesta vida, a alma fosse vencida pela música, pois, se estava presa no cárcere corpóreo, recordando-se e sendo consciente da Música do céu, se esquecesse toda a dura e cansativa lida. Mas se, entáo, o parecesse estranho, temos da Harmonia do céu o testemunho das Sagradas Escrituras, onde o Senhor fala a Jó [cap. 
38, 4-7] dizendo: "Quem narrará as proporçôes ou as vozes dos céus? E quem fará calar o seu concerto?”. E, se me fosse perguntado, como queira, porque táo grande e táo doce som não seja por nós ouvido; outra coisa não saberia responder senão aquilo que diz Cícero [no sexto livro da República] que nossos ouvidos, repletos de tanta harmonia, são surdos, tal como acontece aos habitantes de lugares - como aquele onde precipita o Nilo de altíssima altura (e que se chama de catadupa) - os quais, dada a grandeza do estrondo são, de certo modo, surdos; ou, ainda, tal como o nosso olho náo pode fixar a vista no Sol ficando ofuscado por seus raios, do mesmo modo nossos ouvidos não podem entender a doçura da harmonia dos céus, pela sua excelência e grandiosidade. ${ }^{14}$

Em outro passo (1589, p. 388), Zarlino refere-se à história de Mársias, que segundo a tradição, foi quem encontrou a flauta (ou aulos) atirada por Atenas - deusa que, ao ver que, embora o som do instrumento lhe fosse agradável, a feição indecorosa causada pelo volume das bochechas, infladas pela arte, impedia que ela prosseguisse naquele empreendimento; assim, por tal insatisfação, resolveu jogar, dos céus, o instrumento. Mársias, tendo o encontrado e percebendo a grande capacidade de encantamento da flauta, convenceu-se de que era muito potente. Impudentemente, então, desafiou Apolo para competir consigo sob o julgamento das Musas e com o prêmio de fazer do vencido o que bem quisera. Sua arrogância, no entanto, acabou fazendo-o subestimar o oponente e, vencido pela lira de Apolo, teve como castigo a morte por esfolamento. A origem divina do instrumento garantia que Mársias encantasse e exercesse grande influência sobre seus ouvintes e sua atuação é recorrente na literatura recuperada no Renascimento pelos chamados humanistas. Como outro aspecto desse espelhamento do universo na Música, Zarlino (1589, p. 18) descreve a relação que Boécio profere sobre a distância dos planetas como intervalos musicais; "da Lua à Mercúrio, se perfaz um intervalo de um semitom maior [...], da Lua ao Sol, a distância de dois tons e um semitom”. Há, como se pode verificar, uma equivalência retórica e filosófica, quanto ao espelhamento já citado, no discurso zarliniano: antichi questa opinione per vera, che nelli sacrificij loro vsauano Musicali istrumenti, \& cantauano alcuni Hinni composti di sonori versi, $\mathrm{i}$ quali conteneuano due parti, l'vna delle quali nominauano

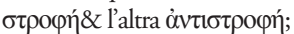
per mostrare li diuersi giri fatti dalle sphere celesti: percioche per l'vna intendeuano il moto, che fa la sphera delle stelle fisse dall'Oriente in Occidente; \& per l'altra li mouimenti diuersi, che fanno l'altre sphere de pianeti procedendo al contrario, dall'Occidente in Oriente. Et con tali istrumenti ancora accompagnauano li corpi de lor morti alla sepoltura: percioche erano di parere, che dopo la morte l'anime ritornassero alla origine della dolcezza della Musica, cioè al cielo. Tal costume osseruarono gia gli Hebrei anticamente nella morte de loro parenti, di che ne hauemo chiarissima testimonianza nell'Euangelio, nel quale è descritta la risuscitatione della figliuola del prencipe della Sinagoga, doue erano musicali istrumenti, a sonatori de i quali comandò il Signor nostro, che più non sonassero. Et faceuano questo (come dice Ambrosio) per osseruare l'vsanza de i loro antichi; liquali in cotal modo inuitauano li circostanti a piangere con esso loro".

14. "Molti ancora haueano opinione, che in questa vita ogni anima fusse vinta per la Musica; et che se bene era nel carcere corporeo rinchiusa, ricordandosi \& essendo consapeuole della Musica del cielo; si domenticasse ogni dura $\&$ noiosa fatica. Ma se ciò ne paresse strano, hauemo dell'harmonia del cielo il 
testimonio delle Sacre lettere, doue il Signore parla a Giobbe dicendo; Chi narrerà le ragioni o voci de Cieli? Et chi farà dormire il loro concento? Et se mi fusse dimandato; onde proceda, che tanto grande \& si dolce suono non sia vdito da noi; altro non saprei rispondere, che quello, che dice Cicerone nel luogo di sopra allegato; Che gli orecchi nostri ripieni di tanta harmonia sono sordi; si come per essempio auiene a gli habitatori di quei luoghi doue il Nilo da monti altissimi precipita, detti Catadupa; i quali per la grandezza del rimbombo mancano del senso dell'vdito. Ouero che si come l'occhio nostro non può fissare lo sguardo nella luce del Sole, restando da i suoi raggi vinta la nostra luce; cosi gli orecchi nostri non possono capire la dolcezza dell'harmonia celeste, per l'eccellenza et grandezza sua".

\section{5. "Ma chi uorrà} esserminar i Cieli nelle loro parti, secondo che con gran diligenza hà fatto Tolomeo, ritrouera (comparate insieme le doditci parti del Zodiaco, nelle quali sono i dodici segni celesti) le consonanze musicali; cioè, la Diatessaron, la Diapente, la Diapason \& l'altre per ordine".
Quem, porém, quiser examinar os Céus em suas divisóes, segundo o que, com grande diligência fez Ptolomeu, encontrará, junto com a comparação das doze partes do Zodíaco, nos quais estão os doze signos celestes, as consonâncias musicais, ou seja, a Diatesseron, a Diapente, a Diapason e as outras, pela ordem. ${ }^{15}$

À guisa de uma conclusão da definição dessa parte da Música Animastica, Zarlino recorda que muito bem fizeram Mercúrio e Terpandro, pois o primeiro, tendo inventado a Lira, ou a Cítara, pôs nela quatro cordas à imitação da Música Mundana, segundo Boécio e Macróbio, a qual se baseia nos quatro Elementos ou, ainda, na variedade das estaçóes do ano. O segundo, porém, ordenou o instrumento com sete cordas à imitação dos sete planetas - e chamou-o de Heptacórdio.

\section{DA MÚSICA HUMANA}

A Música Humana, afirma Zarlino no capítulo VII das Instituiçóes, é aquela Harmonia que pode ser entendida por todas as pessoas no exame e contemplaçáo de si mesmo; que compreende a vivacidade incorpórea da Razáo como um certo temperamento - como o das vozes graves e agudas em uma consonância. Ela é a conjunção das partes da Alma com o Corpo humano, da dimensão racional com aquela irracional. É a Música, em sua dimensão Humana, quem mescla os Elementos com proporção e equilíbrio e, desde o princípio da concepção do ser humano, está presente harmoniosamente.

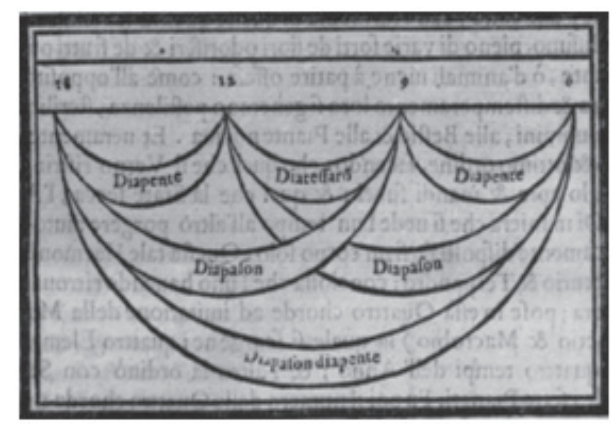

Fig.2: A demonstração por Zarlino, nas Instituiçóes Harmônicas, 1589, p. 22, dos intervalos musicais realizados entre os dias fundamentais concepção humana. 
Como medido pelos médicos - mas também consentido por S. Agostinho - prossegue nosso autor (1589, p. 23), o sêmen humano no corpo da mulher demora seis dias para converter-se em leite, e nove dias para transformar-se em sangue. Ao término de doze dias, já é uma massa de carne sem forma que, pouco a pouco, no décimo oitavo dia, toma forma humana. Em quarenta e cinco dias se conclui, então, a geração com a infusão da Alma intelectiva por Deus. Como vemos na figura 2, o intervalo entre os dias desse processo, segundo Zarlino, equivaleria às harmonias sonoras, proporcionadas como oitava (diapason), quinta (diapente) e quarta (diatesseron). Se pode, igualmente, verificar ainda mais precisamente a Música em sua dimensão Humana, no harmonioso desenvolvimento do ser humano, que de infante se transforma harmoniosamente em velho, dia após dia; muito embora essa mudança concretamente aconteça diante dos nossos olhos, não conseguimos vê-la (não em sua totalidade) mas tão somente compreendê-la, do mesmo modo, talvez, com que não conseguimos ver o espaço que há entre uma voz grave e uma aguda quando se canta, mas apenas entendê-lo através da Razão.

Também os Humores, no seu equilíbrio corpóreo, se podem verificar a harmonia e sua consonância - ou dissonância - que se temperam segundo dirige e governa a Razão à um perfeito fim. Essa harmonia pode ser conhecida nas diversas partes da Alma (1589, p.23):

[...] Se conhece ainda tal harmonia da Alma, ou seja, das suas partes que são o Intelecto, os Sentimentos e o Hábito [...]. ${ }^{16}$

Embora sejam partes fundamentais para a compreensão do conceito de Música que em seu tempo Zarlino frequentava, o autor se compromete com a parte dita Orgânica, que em linhas gerais é, segundo Gozza (2000, p. 10):

A Música Orgância - de 'órgão', se refere tanto aos órgãos do corpo humano que produzem a voz, quanto aos instrumentos musicais fabricados pelo homem - a chamada Musica Instrumentalis de Boécio. Derivada da Música 'orgânica' estáo a 'Harmônica' ou 'Natural' e a 'Artificial', que se refere à harmonia dos instrumentos naturais (da natureza) e a harmonia dos instrumentos artificiais (da Arte [do homem] - e se dividem, primeiramente, em música 'Plana', 'Mensurada', 'Rítmica' e 'Métrica'
16. “[...] Conoscesi ancora tal harmonia dall'Anima; cioè, dalle sue parti, che sono l'Intelletto, $\mathrm{i}$ Sentimenti \& l'Habito $[\ldots] "$. 
17. "L"'organica" - da 'organo', riferibile sia agli organi del corpo umano che producono la voce, sia agli strumenti musicali fabbricati dall'uomo - è la musica instrumentalis di Boezio. Membra della musica "organica" sono l'"harmonica o naturale" e l'"arteficiata", vale a dire l'armonia degli strumenti naturali (natura) e armonia degli strumenti artificiali (arte), la prima divisa in musica "piana", "misurata", "rithmica" e "metrica" (applicabili anche alla musica artificiale), la seconda divisa in base alla natura degli strumenti musicali ossia "da fiato", "da chorde" e "da battere"

18. Tal preceptiva foi objeto de estudo do Mestrado realizado no núcleo de Pós Graduaçãoem Musicologia da ECA-USP, por Fernando Schilliter sob a orientação de Monica Lucas em 2017: "A contemplação de Deus no espelho da música: a música speculativa no tratado "SpeculumMusicae. Um estudo sobre a música speculativa medieval e seu contexto filosófico e teológico a partir da leitura dos capítulos introdutórios do Livro I do tratado".

19. Zarlino riformula la musicologia boeziana, indirizzata ai filosofi, adeguandola alla realtà musicale e ai musicisti; egli unifica musica mondana e musica humana nella musica animastica, distinguendola nettamente dalla musica organica prodotta dall'uomo su questa Terra. La musica instrumentalis ha poi (aplicáveis também à Música Artificial); a segunda divisão, compreende a natureza dos instrumentos musicais, ou seja, os 'de sopro', 'de cordas' e 'de bater'. ${ }^{17}$

Gozza (2000, p. 10), contudo, afirma que a maior transformação que Zarlino propõe sobre a dimensão teórica da Música, relaciona-se ao fundamento e limite das ações do Músico - que mais tarde será chamado de 'Músico Perfeito' em semelhança ao conceito de 'Musicus Perfectissimus' considerado em preceptivas como no Speculum Musicae de Jacobus Leondiensis ${ }^{18}$ - mas atualizando, tanto o conceito de Música, como o de Músico. Se antes, a vocação do Músico Perfeito estava completamente amparada no que Zarlino considera Animástico, com essa modernização conceitual, o foco passa a estar muito mais sobre a dimensão Prática da profissão combinada com o seu profundo conhecimento histórico e retórico:

Zarlino reformula a musicologia de Boécio, endereçada aos filósofos, adequando-a à realidade musical e aos musicistas; ele unifica a música mundana e a música humana na Animástica, distinguindo-a sutilmente da música orgânica produzida pelo homem na Terra. A Musica Instrumentalis tem, portanto, em Zarlino articulaçôes não contempladas na sistematização de Boécio, que levam em consideração a evolução da música nos séculos que separam Zarlino de Boécio. Enfim, o objeto das Instituições Harmônicas é a Musica Instrumentalis, ou seja, a Música 'em particular', separada da música 'Universal', Mundana e Humana, própria dos filósofos. ${ }^{19}$

\section{CONSIDERAÇÓES FINAIS}

Numerosas doutrinas produziram fortuna no pensamento musical durante o Renascimento. Reflexos dessa profusão de tradições, tão diversas quanto particulares, se podem achar na literatura tratadística e suportar diferentes versóes para uma mesma específica questáo. Aos olhos hodiernos o que poderia parecer incongruência ou mesmo confusão - a abundância de argumentos muitas vezes contrários, por exemplo - constitui a operação ordinária dos textos submissos à Instituição Retórica quinhentista, mas não àquele proceder científico surgido após o século XVII. 
O conhecimento da difusão, assim, de diferentes significados para uma mesma palavra nesse período - no caso, do conceito de 'Música' - certamente possibilitará interpretaçóes mais coerentes aos assuntos musicais do Renascimento, circunscrevendo-os ao seu âmbito genético. Nesse horizonte de sentido, portanto, é que se desenvolvem as bases da reformulação e ampliação, proposta principalmente por Gioseffo Zarlino, quanto ao conceito de Músico e Música que se definem em sua obra, sobretudo na visita às autoridades históricas e a circunscrição de novos e decorosos limites para a sua Arte e Ciência.

\section{REFERÊNCIAS BIBLIOGRÁFICAS:}

AGOSTINHO, S. Opera Omnia. Roma: Citta Nuova: s/d.

ARISTÓTELES. De la Politica. Veneza, Gio. Battista Somascho: 1583. Trad. F. Figliucci.

Rettorica et Poetica tradotte di Greco. Tradução de Bernardo Segni. Florença: Lorenzo Torrentino, 1549.

Nicomachean Ethics.Princeton: Princeton University Press, 1984. Trad D. Ross.

Problems. London: Harvard Music Press (Loeb), 1937. Trad. W. S. Hett.

ARTUSI, Giovanni Maria. L'arte del Contraponto. Veneza:Giacomo Vincenti, 1586.

L'Artusi overo delle imperfettioni della moderna musica.Veneza: Giacomo Vincenti, 1600.

BOCCACCIO, Giovanni. La Genealogia de gli Dei.Veneza: Fratelli Zoppini, 1581.Trad. G. Betussi.

BOECIO. Sobre el fundamento de la música. Madrid: Gredos, 2009. in Zarlino articolazioni non contemplate nella sistemazione boeziana, che tengono conto dell'evoluzione della musica nei secoli che separano Zarlino da Boezio. Infine, l'oggetto delle Istitutioni harmoniche è la musica instrumentalis, ossia la musica "in particolare", separata dalla musica "in universale”, mondana e humana, propria dei filosofi. 
CARDOSO, Fernando Schlithler. A contemplação de Deus no espelho da música: a música speculativa no tratado SpeculumMusicae. Um estudo sobre a música speculativa medieval e seu contexto filosófico e teológico a partir da leitura dos capitulos introdutórios do Livro I do tratado. 2017. 308 f. Dissertação (Mestrado em Música) - Departamento de Música da Escola de Comunicação e Artes, Universidade de São Paulo, São Paulo, 2017.

DIRUTA, Girolamo. Il transilvano dialogo sopra il vero modo di sonar organi, et istromenti da pena - Fac-símile -Veneza, 1593 e 1609. Bologna: Forni Editore, 1960.

FERNANDEZ, António. Arte de Musica de Canto Dorgam e Canto Cham\&Proporçoēs de Musica divididas harmonicamente. Lisboa: Pedro Craesbeeck, 1626.

FURLAN, Mauri. A tradução retórica do Renascimento. In: FURLAN, Mauri (org.). Clássicos da Teoria da tradução. Volume 4. Florianópolis: UFSC/NUPLITT, 2006.

GALILEI, Vincenzo. Il Fronimo. Dialogo sopra l'arte del bene intavolare, et rettamente sonare la musica - facsímile -Veneza, 1584. Bologna: Forni Editore, s/d.

GOZZA, Paolo, Number to sound. The musical way to the scientific revolution. Dordrecht-Boston-London: Kluwer Academic Publishers, 2000.

HORÁCIO, Quinto. Ode III. Tradução de Rui Miguel Duarte. Disponível em: <http://marocidental.blogspot.com. br/2012/01/horacio-ode-330.html>. Acesso em: 17 jul. 2017.

LORENZETTI, Stefano. Musica e identità nobiliare nell'italia del Rinascimento: Educazione, mentalità, immaginario. Firenze: Leo S. Olschki, 2003.

MARANS I SISCAR, Gregorio. P. Virgilii Maronis Opera omnia: variis interpretibus et notis illustrata. Valencia: Hermanos de Orga, 1795. 
PLATÃO. Diálogos - Fedro - Cartas - O Primeiro Alcibiades. Belém: Ed. UFPA, 2007.

QUINTILIANO, Marco Fabio. InsititutioOratoria. London: Harvard University Press, 1985.

REZENDE PORTO, Delphim. Girolamodiruta: iltransilvano - diálogo sobre o verdadeiro modo de tocar órgão \& instrumentos de teclado. Um estudo sistemático do Tratado e da Música em princípios do séc. XVII. 2013. 342f. Dissertação (Mestrado) Escola de Comunicaçôes e Artes, Universidade de São Paulo, São Paulo, 2013.

. L'Institutioni Oratorie. Venezia: I Gioliti, 1584. Trad. Oratio Toscanella.

TAMMINGA, Liuwe. Prefazione. In: Musica Nova. Venezia 1540 - Ricercari. Bolonha: Il Levante libreriaeditrice, 2010.

VIRGILIO, Publio. Eneida. Tradução de João Franco Barreto. Lisboa: AntonioCraesbeeck de Mello, 1670.

ZACCONI, Ludovico. Prattica di Musica I e II. Veneza: Bartolomeo Carampello, 1592 e 1619.

ZARLINO, Gioseffo. Istitutione Harmoniche. Veneza: Francesco de' Franceschi, 1558, 1561 e 1589.

. Dimostrationi Harmoniche. Veneza: Francesco de' Franceschi, 1571.

schi, 1588.

Sopplimenti Musicali. Veneza: Francesco de' France- 